\section{Response to clinical and genetic aspects of Ehlers-Danlos syndrome, classic type}

To the Editor:

read with interest the review of the clinical and genetic aspects of Ehlers-Danlos syndrome (EDS) by Malfait et al. ${ }^{1}$ This otherwise excellent review was weakened by the cursory discussion of pain associated with EDS. The authors do not include assessment and characterization of pain in the recommendations for initial evaluation, and pain is only briefly mentioned in management of musculoskeletal manifestations (Antiinflammatory drugs may help with joint pain), prevention of musculoskeletal manifestations (Individuals with muscle hypotonia and joint instability with chronic pain may have to adjust lifestyle and professional choices accordingly), and under emotional support (Emotional support and behavioral and psychological therapy may be indicated to accept and cope... with the long-term chronic pain).

Chronic pain has long been recognized as a clinically important manifestation in all types of EDS..$^{2,3}$ The pain is severe, unremitting, and significantly impacts activities of daily living, sleep, energy levels, and quality of life..$^{3-5}$ More recently, systematic study of pain in EDS has better characterized the contribution of clinical factors to pain in these patients. ${ }^{3}$ Dislocations, joint hypermobility, and previous surgery in ascending order of importance were significantly associated with pain. ${ }^{3}$ Despite these studies, the actual cause of the pain in EDS remains unknown. The patients with EDS followed through my clinic have generally had extensive (and expensive) evaluations including batteries of rheumatologic tests and many imaging studies. Most have been on multiple pain medications, both over the counter and prescription including narcotics, with poor results. They uniformly express frustration as their providers are unfamiliar with EDS and are unaware of the chronic pain associated with the diagnosis. This coupled with the lack of objective findings of joint inflammation or degeneration results in the patients being labeled as hypochondriacs or drug seekers. Referring these patients to multidisciplinary pain clinics and educating the providers at these clinics about EDS and the pain associated with it has resulted in objective improvement in patient's day to day ability to function and subjective improvement in coping and mood. Medication use is generally less and is safer.

To date, no studies have evaluated the relative effectiveness of pain management strategies in EDS. Multidisciplinary pain clinics are considered the standard of care for management of patients with chronic, complex pain. ${ }^{6}$ I think that all patients with EDS should be asked about pain as a routine part of the initial evaluation. All patients with pain that requires regular medication, that interferes with activities of daily living or sleep, or that is identified as affecting quality of life should be referred to a multidisciplinary pain clinic for evaluation and treatment. Furthermore, medical geneticists are obliged to educate the pain clinic about EDS and the pain associated with it. Our lack of understanding of the mechanism of the pain should provide the impetus for more research in this area with the hope that improved treatment would follow.

Marc Williams, MD Clinical Genetics Institute Intermountain Healthcare

Salt Lake City, Utah

Disclosure: The author declares no conflict of interest.

\section{REFERENCES}

1. Malfait F, Wenstrup RJ, DePaepe A. Clinical and genetic aspects of EhlersDanlos syndrome, classic type. Genet Med 2010;12:597-605.

2. Sacheti A, Szemere J, Bernstein B, Tafas T, Schechter N, Tsipouras P. Chronic pain is a manifestation of the Ehlers-Danlos syndrome. J Pain Symptom Manage 1997; 14:88-93.

3. Voermans NC, Knoop H, Bleijenberg G, van Engelen BG. Pain in EhlersDanlos syndrome is common, severe, and associated with functional impairment. J Pain Symptom Manage 2010;40:370-378.

4. Berglund B, Nordström G. Symptoms and functional health status of individuals with Ehlers-Danlos syndrome (EDS). J Clin Rheumatol 2001;7:308314.

5. Rombaut L, Malfait F, Cools A, De Paepe A, Calders P. Musculoskeletal complaints, physical activity and health-related quality of life among patients with the Ehlers-Danlos syndrome hypermobility type. Disabil Rehabil 2010; 32:1339-1345.

6. Morlion B, Walch H, Yihune G, et al. The Pain Associates' International Network Initiative: a novel practical approach to the challenge of chronic pain management in Europe. Pain Pract 2008;8:473-480.

\section{Reply to the letter to the editor by Marc Williams}

\section{To the Editor:}

Thank you for the opportunity to respond to the Letter to the

Editor entitled "Response to clinical and genetic aspects of Ehlers-Danlos syndrome, classic type" by Williams. We agree with Dr. Williams that pain is a clinically important manifestation of Ehlers-Danlos syndrome (EDS). However, we would like to take the opportunity to reply with a few comments.

First, we would like to point out that only few studies have addressed pain in EDS. Moreover, the available studies are limited in size and scope and relate mostly to patients with EDS, hypermobility type. Specific findings in patients with classic EDS are not well documented. ${ }^{1-4}$ Moreover, no evidence-based information on pain management in patients with classic or other types of EDS is currently available.

Second, the pathophysiologic basis of chronic pain in EDS is not well understood. In our clinical experience, no good correlation exists between the degree of hypermobility and the severity of pain. For example, it is our experience that patients with classic EDS often do not suffer from chronic pain, despite presence of severe joint hyperlaxity, whereas patients with EDS, hypermobility type, can suffer from chronic and progressive disabling pain, even if the joint hypermobility is limited. A recent study from Voermans et al. ${ }^{3}$ confirms our observation that chronic pain is more prevalent and severe in the hypermobility than the classic type of EDS, suggesting that factors other than the degree of joint hypermobility contribute to the pain.

Since this review covers the classic, and not the hypermobility type of EDS, we did not expand too much on the discussion of pain. Nevertheless, we fully agree with Dr. Williams that all patients with EDS should be asked about pain as a routine part of their initial evaluation and that multidisciplinary treatment of pain should be a prominent aspect of symptomatic management of patients with EDS. Studies addressing prevalence, pathophysiology, and treatment strategies of pain in all subtypes of EDS are urgently needed to improve care of patients with EDS.

Fransiska Malfait, MD, PhD Centre for Medical Genetics Ghent University Hospital De Pintelaan, Ghent, Belgium 
Richard J. Wenstrup, MD Myriad Genetics Laboratories, Inc. Salt Lake City, Utah

Anne De Paepe, MD, PhD

Centre for Medical Genetics Ghent University Hospital De Pintelaan, Ghent, Belgium Disclosure: The authors declare no conflict of interest.

\section{REFERENCES}

1. Sacheti A, Szemere J, Bernstein B, Tafas T, Schechter N, Tsipouras P Chronic pain is a manifestation of the Ehlers-Danlos syndrome. J Pain Symptom Manage 1997;14:88-93.

2. Berglund B, Nordström G. Symptoms and functional health status of individuals with Ehlers-Danlos syndrome (EDS). J Clin Rheumatol 2001;7:308-314.

3. Voermans NC, Knoop H, Bleijenberg G, van Engelen BG. Pain in EhlersDanlos syndrome is common, severe, and associated with functional impairment. J Pain Symptom Manage 2010;40:370-378.

4. Rombaut L, Malfait F, Cools A, De Paepe A, Calders P. Musculoskeletal complaints, physical activity and health-related quality of life among patients with the EhlersDanlos syndrome hypermobility type. Disabil Rehabil 2010;32:1339-1345. 